\title{
Complication rates of percutaneous brachial artery puncture: effect of live ultrasound guidance
}

\author{
K. Appelt ${ }^{1 *+} \mathbb{D}$, M. Takes ${ }^{1 \dagger}$, C. J. Zech ${ }^{1}$, KA Blackham $^{1}$ and T. Schubert ${ }^{1,2}$
}

\begin{abstract}
Purpose: The current literature on the use of brachial artery access is controversial. Some studies found increased puncture site complications. Others found no higher complication rates than in patients with femoral or radial access. The purpose of this study was to determine the impact of ultrasound (US)-guidance on access site complications.
\end{abstract}

Materials and methods: This is a single-center retrospective study of all consecutive patients with brachial arterial access for interventional procedures. Complications were classified into minor complications (conservative treatment only) and major complications (requiring surgical intervention). The brachial artery was cannulated in the antecubital fossa under US-guidance. After the intervention, manual compression or closure devices, both followed by a compression bandage for $3 \mathrm{~h}$, either achieved hemostasis.

Results: Seventy-five procedures in seventy-one patients were performed in the study period using brachial access. Access was successful in all cases (100\%). Procedures in different vascular territories were performed: neurovascular (10/13.5\%), upper extremity (32/43.2\%), visceral (20/27.0\%), and lower extremity (12/16.3\%). Sheath size ranged from 3.2F to 8F (mean: 5F). Closure devices were used in 17 cases (22.7\%). In total, six complications were observed (8.0\%), four minor complications (5.3\%, mostly puncture site hematomas), and two major complications, that needed surgical treatment (2.7\%). No brachial artery thrombosis or upper extremity ischemia occurred.

Conclusion: Exclusive use of US-guidance resulted in a low risk of brachial artery access site complications in our study compared to the literature. US-guidance has been proven to reduce the risk of access site complications in several studies in femoral access. In addition, brachial artery access yields a high technical success rate and requires no additional injection of spasmolytic medication. Sheath size was the single significant predictor for complications.

Keywords: Brachial access, Ultrasound, Ultrasound-guidance, Endovascular, Intervention, Angiography

\footnotetext{
* Correspondence: Konrad.appelt@usb.ch

${ }^{\dagger} \mathrm{K}$. Appelt and M. Takes contributed equally to this work.

'Radiology and Nuclear Medicine Clinic, University Hospital Basel, Basel,

Switzerland

Full list of author information is available at the end of the article
}

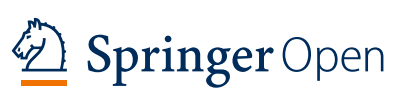

(c) The Author(s). 2021 Open Access This article is licensed under a Creative Commons Attribution 4.0 International License, which permits use, sharing, adaptation, distribution and reproduction in any medium or format, as long as you give appropriate credit to the original author(s) and the source, provide a link to the Creative Commons licence, and indicate if changes were made. The images or other third party material in this article are included in the article's Creative Commons licence, unless indicated otherwise in a credit line to the material. If material is not included in the article's Creative Commons licence and your intended use is not permitted by statutory regulation or exceeds the permitted use, you will need to obtain permission directly from the copyright holder. To view a copy of this licence, visit http://creativecommons.org/licenses/by/4.0/. 


\section{Introduction}

Since the advent of endovascular procedures, transfemoral access via the common femoral artery has been the preferred access site (Judkins 1967). However, since the first transradial access was described in 1989 by Campeau (Campeau 1989), there is a steady increasing approach of this technique, especially in cardiac- and recently also in neuro and body-interventions. In 2018 the American Heart Association (AHA) updated their recommendation to a "radial first" strategy due to level 1 evidence (Mason et al. 2018; Brueck et al. 2009) after randomized trials showed significantly reduced puncture site bleeding complications when using sheath sizes of up to 7 French (F), as well as reduced all-cause mortality (Valgimigli et al. 2015; Jolly et al. 2011). Additionally, ultrasound (US)-guidance was shown to improve the success rate of first-attempt arterial punctures while decreasing the time, as well as lowering the local complications such as hematomas from 3.4\% to 1.4\% (Shiloh et al. 2011; Seto et al. 2010a; 2010b).

However, transradial access can be limited not only by the vessel size prohibiting larger sheath placement than $7 \mathrm{~F}$ but also the prolonged distance from the puncture site to the target area which may especially problematic when access to the abdominal or lower extremities is required (Chen and Peterson 2019). Moreover, radial artery spasm, radial or ulnar artery occlusion, as well radial artery tortuosity or anomalies can impede the transradial access (Mason et al. 2018; Seto et al. 2015; Pancholy et al. 2016) The major complication rate of radial arterial access is described as low as $0.5 \%$, whereas the crossover rate is $4.9 \%$ (Burzotta et al. 2012).

The current literature on the use of a brachial access is controversial (Benit et al. 1997; Alvarez-Tostado et al. 2009). Whereas some studies found increased puncture site complications from 7 to $11 \%$ (Watkinson and Hartnell 1991; Grollman and Marcus 1988) up to 36\% (Benit et al. 1997; Alvarez-Tostado et al. 2009), mainly consisting of bleeding complications and pseudoaneurysms (Watkinson and Hartnell 1991; Grollman and Marcus 1988; Heenan et al. 1996; Armstrong et al. 2003; Stavroulakis et al. 2016), other studies found no higher complication rates than in patients with femoral of transradial access (Grollman and Marcus 1988; Heenan et al. 1996).

Therefore, the aim of this study was to determine the impact of US-guidance on the rate of access site complications in a consecutive cohort of patients with brachial access in our institute. We hypothesized that the rate of complications will be lower than in comparable studies without US-guidance and that brachial access can be used for a wide variety of endovascular interventions successfully and safely.

\section{Methods}

\section{Data collection}

This is a single-center retrospective review. From January 2009 until January 2021, all patients who underwent an angiogram via brachial arterial access were reviewed. The local ethics committee of the University of Basel approved the study. All study protocols and procedures were conducted in accordance with the Declaration of Helsinki.

Data were extracted from the radiological information system (RIS) and the medical charts of the patients and included patient demographics, interventional body area, interventional technique, sheath and catheter size, peri- and post-interventional complications, as well as major adverse events, mainly death within 10 days.

Complications were further classified into minor complications (conservative treatment only) and major complications (requiring surgical intervention).

\section{Procedural details}

The type of approach and puncture site was individually chosen by the interventional radiologist depending on the type of procedure.

The arm was extended on a specific arm board (STARSystem, Adept Medical) and the brachial artery was cannulated in the antecubital fossa with a micropuncture set (Radifocus ${ }^{\circledR}$ Introducer II Transradial Kit, Terumo) using a $22 \mathrm{G}$ Needle and a $0.18 \mathrm{in}$. wire after local anesthetic infiltration under live ultrasoundguidance. Spasmolytic agents were not applied, as mostly been using in radial access. If necessary, a larger sheath was subsequently inserted in Seldinger technique.

After completion of intervention, hemostasis was either achieved by manual compression or closure devices, followed by a compression bandage for $3 \mathrm{~h}$. The decision was made by the interventionalist, based on various factors like puncture site, vessel size, sheath size and experience. Postprocedural evaluation of the puncture site and the peripheral perfusion was performed by default $1,2,3$, and $6 \mathrm{~h}$ after finishing the procedure.

\section{Follow up}

The follow up of the patients was performed by the attending disciplines. To assess the patient history, all the clinical data from the time of the intervention until 1 year after were investigated.

\section{Statistical analysis}

For the statistical analysis, major and minor complications were grouped. Continuous variables are presented as means \pm standard deviation, while categorical data 
are given as the counts (percentages). For the response variable complication $(y / n)$, a general linear model was fit with anticoagulation $(y / n)$, closure device $(y / n)$ and sheath size (French, numeric) as predictors for which separate intercepts were fit. The level of significance was set at 0.05 . The data were analyzed in $r$ Project (" $R$ Foundation", Vienna, Austria).

\section{Results}

\section{Data distribution}

Seventy-five procedures via brachial artery approach in seventy-one patients were performed. The baseline demographics and patient characteristics can be seen in Table 1. One patient was excluded from the study because of death in the peri-operative period of his underlying disease, due to missing clinical follow-up of access site complications. Fourteen procedures (18.7\%) were emergencies. The interventional target area was diverse with nine different vascular territories (Table 2). In 58 of the interventions (77.3\%), manual compression followed by a compression bandage was applied for hemostasis. In 17 interventions (22.7\%), a closure device $\left(n=9\right.$ Angio-Seal $^{\circ}$ VIP, Terumo Corporation; $n=7$ Mynx; CardinalHealth, $n=1$ Starclose, Abbott) was utilized. Mean follow up was up to 3 months after the procedure.

\section{Complications}

In total, six complications were observed, four minor (5.3\%) and two major (2.7\%) complications (Tables 3 and 4).

The four minor complications included three hematomas at the puncture site, which were treated conservative without blood transfusion, and one pseudoaneurysm, which could be successfully treated with ultrasoundguided compression.

The first major complication was a surgically treated pseudoaneurysm. In this case, a $6 \mathrm{~F}$ sheath was used and manual compression for bleeding control at the access site. The second major complication consisted of an abscess at the puncture site that required surgical drainage. In this case, a $6 \mathrm{~F}$ sheath was used, and a $6 \mathrm{~F}$ Mynx closer device.

Table 1 Baseline demographics and patientcharacteristics

\begin{tabular}{ll}
\hline Variables & Percentage or mean \\
\hline Age, $y$ & 66.9 (range 30 to 93) \\
Female & $38(51.4 \%)$ \\
Sheath size & $5 \mathrm{~F}$ (range 3F to 8F) \\
Major Complications & $2.7 \%$ \\
Minor Complications & $5.4 \%$ \\
\hline
\end{tabular}

Table 2 Treated vascular territories

\begin{tabular}{ll}
\hline Arterial region treated & Distribution \\
\hline Upper Extremity retrograde & 25 \\
Visceral & 15 \\
Head and Neck & 10 \\
Upper Extremity antegrade & 7 \\
Pelvis & 6 \\
Lower extremity & 6 \\
Kidney & 4 \\
Bronchial arteries & 1 \\
Aorta & 1 \\
\hline
\end{tabular}

\section{Statistical analysis}

The estimate, standard error, $\mathrm{z}$-value and $p$-value are summarized in Table 5. According to the general linear model, none of the predictors reached statistical significance. However, sheath size showed a $p$-value of 0.084 (two-tailed hypothesis). For a one-tailed hypothesis, the $p$-value for the predictor sheath size was 0.04. Mean sheath size in all complications was 5.66F (range: 4F $6 \mathrm{~F})$, mean sheath size for the remaining cohort was 4.86F (range $2.7 \mathrm{~F}-8 \mathrm{~F}$ ).

\section{Discussion}

In this retrospective study, we report our experience with ultrasound guided brachial artery access for endovascular procedures (Figs. 1 and 2). The major finding of the study is a low rate of access site complications using ultrasound guidance for brachial artery access. Especially, no case of upper extremity ischemia or brachial artery thrombosis occurred in our cohort. Larger sheath size was a significant predictor of complications. However, the application of a closure device did not result in a lower or higher complication rate.

Our results indicate that the consistent use of ultrasound guide for brachial artery access results in a low number of access site complications (Fig. 3).

Table 3 In total six complications occurred in 74 procedures

\begin{tabular}{lll}
\hline Complication & Occurrences & Treatment \\
\hline Hematoma & 3 & Conservative \\
Pseudoaneurysm & 2 & One surgically, one conservative \\
Access site infection & 1 & Surgically \\
Bleeding & 0 & \\
Arterial thrombosis & 0 & \\
Nerve injury & 0 & \\
Unable to reach lesion & 0 & \\
\hline
\end{tabular}


Table 4 The six complication in more details

\begin{tabular}{llllll}
\hline & Complication & Procedure & $\begin{array}{l}\text { Sheath } \\
\text { size }\end{array}$ & Hemostasis & Consequence \\
\hline Major & abscess & neurovascular & $6 \mathrm{~F}$ & Mynx & Surgical treatment \\
Major & pseudoaneurysma & visceral & $6 \mathrm{~F}$ & manual & Surgical treatment \\
Minor & pseudoaneurysma & lower & $6 \mathrm{~F}$ & manual & conservative (ultrasound compression) \\
& & extremity & & manual & conservative \\
Minor & hematoma & upper extremity & $6 \mathrm{~F}$ & manual & conservative \\
Minor & hematoma & visceral & $4 \mathrm{~F}$ & manual & conservative \\
Minor & hematoma & lower extremity & $6 \mathrm{~F}$ & &
\end{tabular}

Especially major complications that require surgical intervention appeared at a low rate of $2.7 \%$. Moreover, brachial artery thrombosis resulting in upper extremity ischemia did not occur in our series. We hypothesize that with US-guidance, the brachial artery is punctured at the optimal location in proximity to the bony landmark of the medial humeral condyle away from arterial bifurcations. This leads to an optimal compressibility against the medial humeral condyle after removal of the sheath.

It has been reported that brachial access is associated with a higher degree of access-related morbidity compared to femoral and radial access (Watkinson and Hartnell 1991; Stavroulakis et al. 2016; Madden et al. 2019; Franz et al. 2017). Overall complication rates as high as $36 \%$ have been described for brachial arterial access with major complications (hematoma, thrombosis, pseudoaneurysm, arteriovenous fistula, permanent neurologic deficit, and dissection) as high as $7 \%$ to $11 \%$ (Alvarez-Tostado et al. 2009; Armstrong et al. 2003; Franz et al. 2017).

However, recent studies have shown that BA access can be a safe and effective alternative to femoral access, with complication rates of between $1.3 \%$ and $3.4 \%$ reported (Franz et al. 2017).

One of these studies showed, that access-related complications increase with sheath size (Kret et al. 2016). This finding could be reproduced in our series.

Table 5 General linear model with anticoagulation (y/n), closure device $(y / n)$ and sheath size (French, numeric) as predictors for which separate intercepts

\begin{tabular}{lllll}
\hline Coefficients & Estimate & Std. Error & $\mathbf{z}$ value & $\boldsymbol{p}$-value \\
\hline Intercept & 7.36 & 3.32 & 2.22 & $\mathbf{0 . 0 2 6}$ * \\
Anticoagulation $(\mathrm{y} / \mathrm{n})$ & 0.28 & 0.96 & 0.3 & 0.76 \\
Closure device & 1.46 & 1.24 & 1.17 & 0.24 \\
Sheath size & -0.86 & 0.5 & -1.73 & 0.084 \\
\hline
\end{tabular}

The major complication rate in our patients was $2.7 \%$ (2 patients out of 74 procedures). No permanent deficit resulted from both complications which could be surgically resolved (one pseudoaneurysm, one access site abscess).

The effect of live ultrasound guidance has not been assessed well for brachial artery access, however, several studies demonstrated a significant lower access site complication rate at the femoral artery when using live ultrasound guidance (Shiloh et al. 2011; Seto et al. 2010a; Seto et al. 2015; Inagaki et al. 2018). The data review of our last 12 years of ultrasound-guided brachial access demonstrated a $100 \%$ access success rate, similar to the literature (Gan et al. 2010).

For access site closing, manual compression was used in $76 \%$ of cases. In the remaining $24 \%$, vascular closing devices were utilized (Angio-Seal ${ }^{\circ}$ VIP, Terumo Corporation, Tokyo / Mynx, and Starclose, Abbott). Currently, no vascular closing devices are intended for use in the brachial artery. However, some studies which reviewed off-label use in the brachial artery indicate these are likely safe (Lupattelli et al. 2008; Mirza et al. 2014). That coincides with our experience. No case of closing device failure or complications related to the closing device occurred in our series.

Arterial access at the upper extremity allows earlier mobilization compared with femoral access improving patient comfort (Armstrong et al. 2003; Franz et al. 2017). The advantages of brachial artery access compared to radial access are the bigger dimension of the puncture site vessel, as well as that standard catheter material can be used, in contrast to radial access, where shaft length of more than $100 \mathrm{~cm}$ is needed) and material for treatment of e.g. femoral lesions might be problematic even with 150 $\mathrm{cm}$ devices (Franz et al. 2017). Spasmolytics are generally not necessary for brachial access. Hence, in emergency situations, brachial artery access is swiftly achieved. 


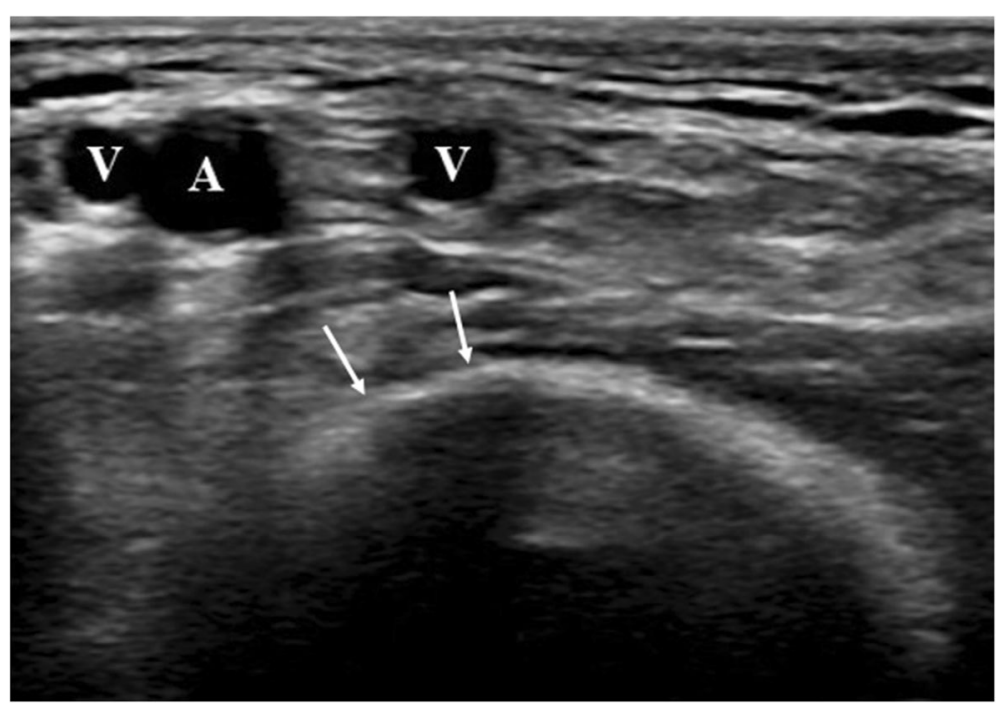

Fig. 1 Transversal ultrasound picture of the A. brachialis (A) in the cubital fossa. The distal humerus (white arrows) forms an abutment, which helps for manual compressions. Two brachial veins $(V)$ often accompany the distal A. brachialis

\section{Limitations}

This review has some limitations. This a retrospective, nonrandomized study. The access site choice was by interventionalist preference.

Additionally, our study was limited by its relatively small sample size. We believe that additional studies with larger sample sizes are necessary, to confirm our low complication rates.

Our overall complication rate of $5.4 \%$, with $2.7 \%$ requiring surgical intervention, is certainly comparable to standard femoral access, which is reported to be between 1.3\% and 3.4\% (Derubertis et al. 2007; Black et al. 2005; Archbold et al. n.d.; Piper et al. 2003). However, further studies of brachial artery access should be compared with a matched control group of femoral access.

\section{Conclusions}

Our 12-year review of brachial access under live ultrasound guidance demonstrated that brachial access is a safe and reliable alternative to radial and femoral artery access. It offers a wide variety of endovascular interventions in every major peripheral arterial region. Live ultrasound guidance facilitated successful arterial access

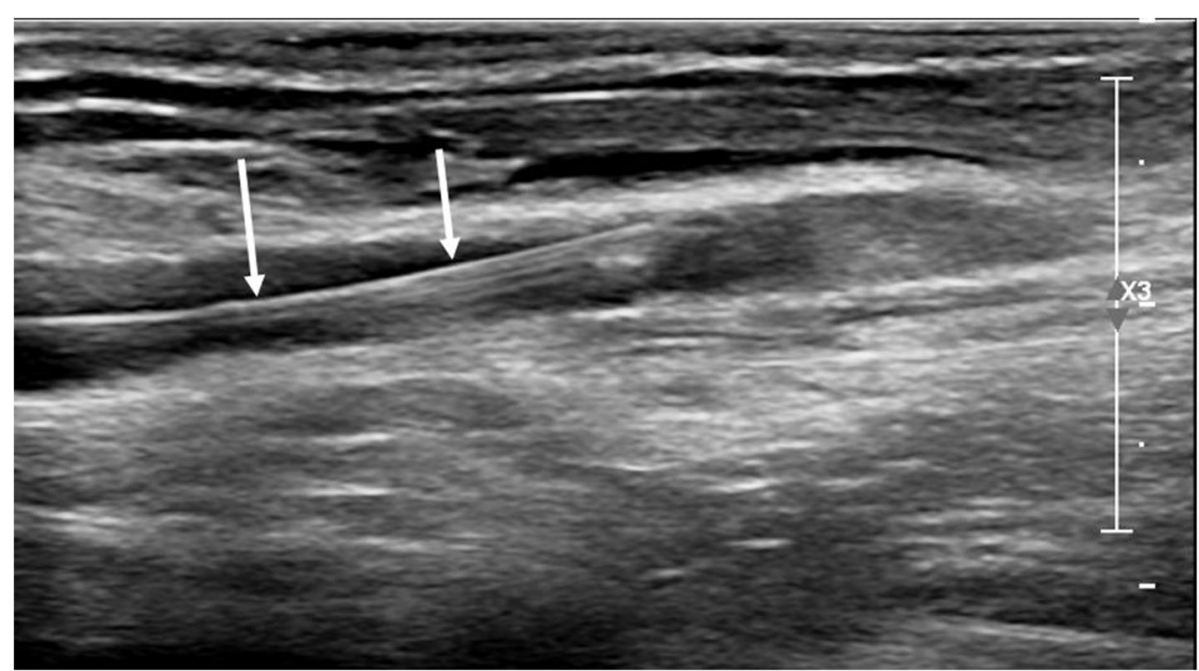

Fig. 2 Longitudinal ultrasound picture of 19G puncture needle and guidewire (white arrows), which was inserted under live ultrasound guidance 


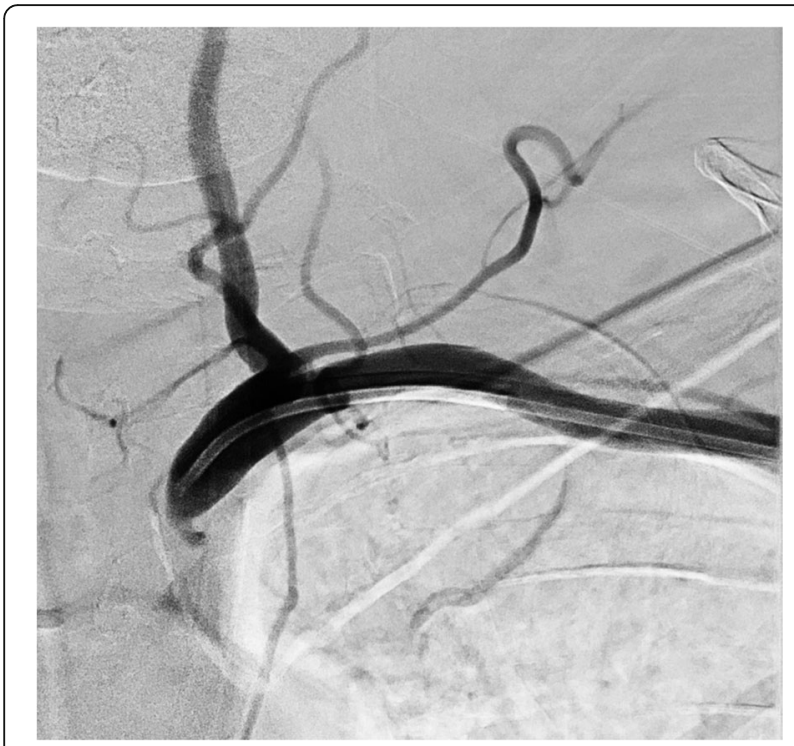

Fig. 3 Digital subtraction angiogram (DSA) of a high-grade subclavian stenosis, treated with retrograde brachial access

and reduced clinical complications. Future prospective and randomized studies could be completed to confirm its low complication rate, to be able to benefit from primary brachial arterial access.

\section{Authors' contributions}

All authors contributed to the paper. The author(s) read and approved the final manuscript.

\section{Funding}

No funding.

\section{Declarations}

\section{Ethics approval and consent to participate}

The ethic approval was given by the local ethics committee.

\section{Consent for publication}

The consent for publication is given by all authors.

\section{Competing interests}

There is no conflict of interest.

\section{Author details}

'Radiology and Nuclear Medicine Clinic, University Hospital Basel, Basel, Switzerland. ${ }^{2}$ Department of Neuroradiology, University Hospital Zurich, Zürich, Switzerland.

Received: 30 July 2021 Accepted: 27 September 2021

Published online: 11 October 2021

\section{References}

Alvarez-Tostado JA, Moise MA, Bena JF, Pavkov ML, Greenberg RK, Clair DG, Kashyap VS (2009) The brachial artery: a critical access for endovascular procedures. J Vasc Surg 49(2):378-385. Available from:. https://doi.org/10.101 6/j.jvs.2008.09.017

Archbold RA, et al (2004) Clinical review Radial artery access for coronary angiography and percutaneous coronary intervention. BMJ 329(7463):443-6. https://doi.org/10.1136/bmj.329.7463.443,

Armstrong PJ, Han DC, Baxter JA, Elmore JR, Franklin DP (2003) Complication rates of percutaneous brachial artery access in peripheral vascular angiography. Ann Vasc Surg 17(1):107-110. https://doi.org/10.1007/s10016-001-0339-6
Benit E, Missault L, Eeman T, Carlier M, Muyldermans L, Materne P, Lafontaine P de Keyser J, Decoster O, Pourbaix S, Castadot M, Boland J (1997) Brachial, radial, or femoral approach for elective Palmaz-Schatz stent implantation: a randomized comparison. Catheter Cardiovasc Diagn 41(2):124-130. https:// doi.org/10.1002/(SICI) 1097-0304(199706)41:2<124::AID-CCD3>3.0.CO;2-9

Black JH, LaMuraglia GM, Kwolek CJ, Brewster DC, Watkins MT, Cambria RP (2005) Contemporary results of angioplasty-based infrainguinal percutaneous interventions. J Vasc Surg 42(5):932-939. https://doi.org/1 0.1016/j.jvs.2005.06.024

Brueck M, Bandorski D, Kramer W, Wieczorek M, Höltgen R, Tillmanns H. A Randomized Comparison of Transradial Versus Transfemoral Approach for Coronary Angiography and Angioplasty. JACC Cardiovasc Interv. 2009;2(11): 1047-1054

Burzotta F, Trani C, Mazzari MA, Tommasino A, Niccoli G, Porto I, Leone AM, Tinelli G, Coluccia V, de Vita M, Brancati M, Mongiardo R, Schiavoni G, Crea F (2012) Vascular complications and access crossover in 10,676 transradial percutaneous coronary procedures. Am Heart J 163(2):230-238. Available from: https://doi.org/10.1016/j.ahj.2011.10.019

Campeau L (1989) Percutaneous radial artery approach for coronary angiography. Catheter Cardiovasc Diagn 16(1):3-7. https://doi.org/10.1002/ccd.1810160103

Chen BYSH, Peterson EC (2019) Pearls and pitfalls: radial first for Neurointervention. Endovasc TODAY 18(11):42-46

Derubertis BG, Faries PL, Mckinsey JF, Chaer RA, Pierce M, Karwowski J, et al. Shifting paradigms in the treatment of lower extremity vascular disease a report of 1000 percutaneous interventions. 2007

Franz RW, Tanga CF, Herrmann JW (2017) Treatment of peripheral arterial disease via percutaneous brachial artery access. J Vasc Surg 66(2):461-465. Available from:. https://doi.org/10.1016/j.jvs.2017.01.050

Gan HW, Yip HK, Wu CJ (2010) Brachial approach for coronary angiography and intervention: totally obsolete, or a feasible alternative when radial access is not possible? Ann Acad Med Singap 39(5):368-373

Grollman JH, Marcus R (1988) Transbrachial arteriography: Techiques and complications. Cardiovasc Intervent Radiol 11(1):32-35. https://doi.org/10.1007/BF02577022

Heenan SD, Grubnic S, Buckenham TM, Belli AM (1996) Transbrachial arteriography: indications and complications. Brain Lang 51(3):205-209. https://doi.org/10.1016/S0009-9260(96)80324-2

Inagaki E, Farber A, Siracuse JJ, Mell MW, Rybin DV, Doros G et al (2018) Routine use of ultrasound guidance in femoral arterial access for peripheral vascular intervention decreases groin hematoma rates in highvolume surgeons. Ann Vasc Surg 51:1-7. Available from. https://doi.org/1 0.1016/j.avsg.2018.02.008

Jolly SS, Yusuf S, Cairns J, Niemelä K, Xavier D, Widimsky P, Budaj A, Niemelä M, Valentin V, Lewis BS, Avezum A, Steg PG, Rao SV, Gao P, Afzal R, Joyner CD, Chrolavicius S, Mehta SR (2011) Radial versus femoral access for coronary angiography and intervention in patients with acute coronary syndromes ( RIVAL ): a randomised, parallel group, multicentre trial. Lancet 377(9775):1409-1420. Available from:. https://doi.org/10.1016/ S0140-6736(11)60404-2

Judkins MP (1967) Selective coronary arteriography. I. a percutaneous transfemoral technic. Radiology. 89(5):815-824. https://doi.org/10.1148/89.5.815

Kret MR, Dalman RL, Kalish J, Mell M (2016) Arterial cutdown reduces complications after brachial access for peripheral vascular intervention. J Vasc Surg 64(1):149-154. Available from:. https://doi.org/10.1016/j.jvs.2016.02.019

Lupattelli T, Clerissi J, Clerici G, Minnella DP, Casini A, Losa S, Faglia E (2008) The efficacy and safety of closure of brachial access using the AngioSeal closure device: experience with 161 interventions in diabetic patients with critical limb ischemia. J Vasc Surg 47(4):782-788. https://doi.org/10.1 016/j.jvs.2007.11.050

Madden NJ, Calligaro KD, Zheng H, Troutman DA, Dougherty MJ (2019 Apr 1) Outcomes of brachial artery access for endovascular interventions. Ann Vasc Surg 56:81-86. https://doi.org/10.1016/j.avsg.2018.07.061

Mason PJ, Shah B, Tamis-Holland JE, Bittl JA, Cohen MG, Safirstein J, Drachman DE, Valle JA, Rhodes D, Gilchrist IC (2018) An Update on Radial Artery Access and Best. Circ Cardiovasc Interv 11:1-21

Mirza AKH, Steerman SN, Ahanchi SS, Higgins JA, Mushti S, Panneton JM (2014) Analysis of vascular closure devices after transbrachial artery access. Vasc Endovascular Surg 48(7-8):466-469 [cited 2021 May 1] Available from: https://journals.sagepub.com/doi/abs/10.1177/1538574414551576

Pancholy SB, Bernat I, Bertrand OF, Patel TM (2016) Prevention of Radial Artery Occlusion After Transradial Catheterization: The PROPHET-II Randomized Trial. JACC Cardiovasc Interv 9(19):1992-1999 
Piper WD, Malenka DJ, Ryan TJ, Shubrooks SJ, O'Connor GT, Robb JF et al (2003) Predicting vascular complications in percutaneous coronary interventions. Am Heart J 145(6):1022-1029. https://doi.org/10.1016/50002-8703(03)00079-6 Seto AH, Abu-Fadel MS, Sparling JM, Zacharias SJ, Daly TS, Harrison AT, Suh WM, Vera JA, Aston CE, Winters RJ, Patel PM, Hennebry TA, Kern MJ (2010a) Realtime ultrasound guidance facilitates femoral arterial access and reduces vascular complications: FAUST (femoral arterial access with ultrasound trial). JACC Cardiovasc Interv 3(7):751-758. https://doi.org/10.1016/j.jcin.2010.04.015

Seto AH, Roberts JS, Abu-Fadel MS, Czak SJ, Latif F, Jain SP, Raza JA, Mangla A, Panagopoulos G, Patel PM, Kern MJ, Lasic Z (2015) Real-time ultrasound guidance facilitates transradial access: RAUST (radial artery access with ultrasound trial). JACC Cardiovasc Interv. 8(2):283-291. https://doi.org/10.101 6/j.jcin.2014.05.036

Shiloh AL, Savel RH, Paulin LM, Eisen LA (2011) Ultrasound-guided catheterization of the radial artery: a systematic review and meta-analysis of randomized controlled trials. Chest 139(3):524-529. Available from:. https://doi.org/10.13 78/chest.10-0919

Stavroulakis K, Usai MV, Torsello G, Schwindt A, Stachmann A, Beropoulis E, Bisdas T (2016) Efficacy and safety of transbrachial access for iliac endovascular interventions. J Endovasc Ther 23(3):454-460. https://doi.org/10.1177/152 6602816640522

Valgimigli M, Gagnor A, Calabró P, Frigoli E, Leonardi S, Zaro T, Rubartelli P, Briguori C, Andò G, Repetto A, Limbruno U, Cortese B, Sganzerla P, Lupi A, Galli M, Colangelo S, lerna S, Ausiello A, Presbitero P, Sardella G, Varbella F, Esposito G, Santarelli A, Tresoldi S, Nazzaro M, Zingarelli A, de Cesare N, Rigattieri S, Tosi P, Palmieri C, Brugaletta S, Rao SV, Heg D, Rothenbühler M, Vranckx P, Jüni P (2015) Radial versus femoral access in patients with acute coronary syndromes undergoing invasive management : a randomised multicentre trial. Lancet. 385(9986):2465-2476. https://doi.org/10.1016/S01406736(15)60292-6

Watkinson AF, Hartnell GG (1991) Complications of direct brachial artery puncture for arteriography: a comparison of techniques. Clin Radiol 44(3): 189-191. https://doi.org/10.1016/S0009-9260(05)80868-2

\section{Publisher's Note}

Springer Nature remains neutral with regard to jurisdictional claims in published maps and institutional affiliations.

\section{Submit your manuscript to a SpringerOpen ${ }^{\circ}$ journal and benefit from:}

- Convenient online submission

- Rigorous peer review

- Open access: articles freely available online

High visibility within the field

- Retaining the copyright to your article

Submit your next manuscript at $\boldsymbol{\nabla}$ springeropen.com 